A.

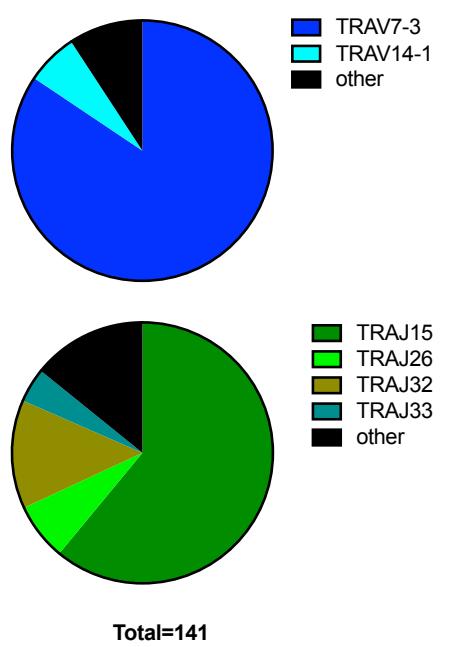

D.

\section{L1 mouse}

TCRa

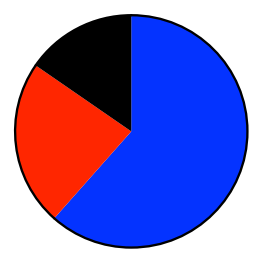

Total $=13$

TCR $\beta$

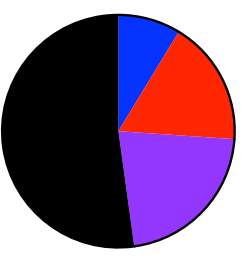

Total $=23$
B.

C.

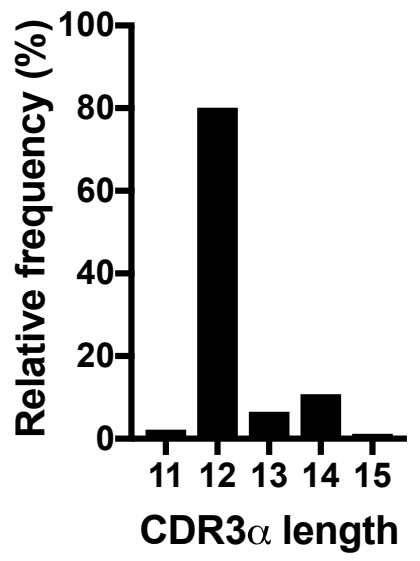

L2 mouse

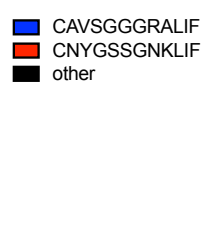

CASSLDRENSDYTF CASSPDRGNTGQLYF - other
111 of 140 sequences with $C D R 3 a=12$

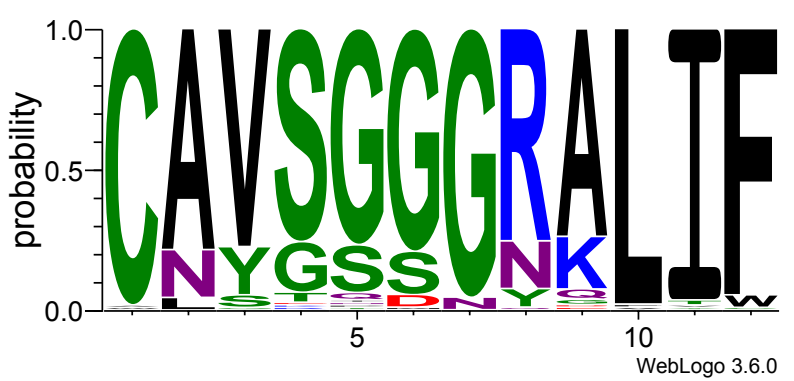

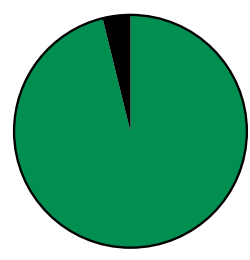

Total $=\mathbf{2 6}$

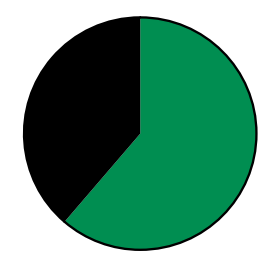

Total $=31$

$\square$ CASSQDRENSDYTF other

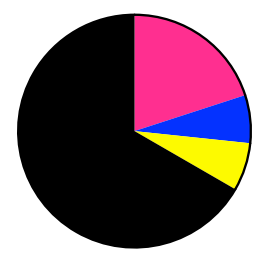

Total=15

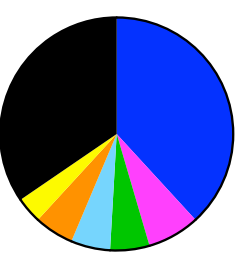

CAVSGGGRALIF $\square$ CAPLNTGNYKYVF $\square$ CAVGNMGYKLTF CAVSPYNVLYF CAVTNNYAQGLTF CAVSQGGRALIF other

E.

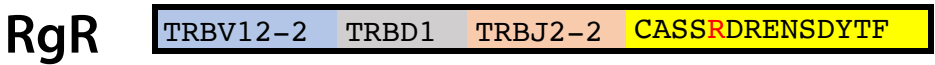

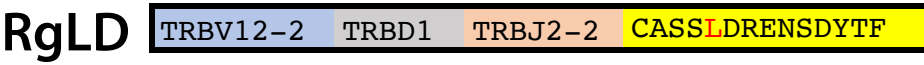

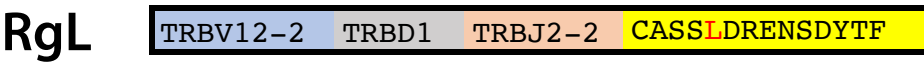

\begin{tabular}{lllll} 
RgQ TRBV2 & TRBD1 & TRBJ2-2 & CASSODRENSDYTF \\
\hline
\end{tabular}

\begin{tabular}{lllll} 
RgP TRBV2 & TRBD1 & TRBJ2-2 & CASSPDRGNTGQLYF \\
\hline
\end{tabular}

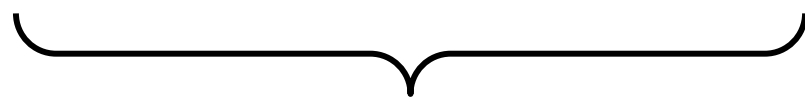

TCRa

\begin{tabular}{|c|c|c|}
\hline CAVSQGGRALIF & TRAV7-3 & TRAJ15 \\
\hline CAVSGGGRALIF & TRAV7D-3 & TRAJ15 \\
\hline CAVSGGGRALIF & TRAV7-3 & TRAJ 15 \\
\hline CAVSTGGRALIF & TRAV7D-3 & TRAJ15 \\
\hline CNYGSSGNKLIF & TRAV7-3 & TRAJ32 \\
\hline
\end{tabular}

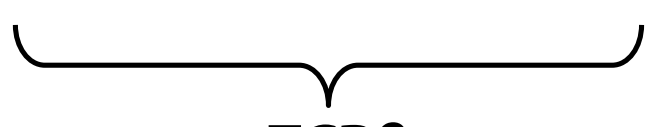

TCR $\beta$ 